\title{
The Research of Formations Intended to the Prevention of Lateral Strain of Columns
}

\author{
Cemal Eyyubov ${ }^{1}$, Mehmet Hasnalbant ${ }^{2}$ and İsa Eyyubov ${ }^{3}$ \\ 1. Department of Civil Engineering, Faculty of Engineering, Erciyes University, Kayseri 38010, Turkey \\ 2. Institute of Natural and Applied Science, Erciyes University, Kayseri 38010, Turkey \\ 3. Azerbaijan Research Institute of Building Materials and Engineering Constructions, Baku AZ 10104, Azerbaijan
}

\begin{abstract}
In this paper, the research for the constructive formations preventing the buckling of the columns is being covered. Especially, the behavior of the constructive support elements which are used during the design of the industry building's columns is analyzed. The preparation of constructive formations which is intended to the prevention of changing shape and the proposals aimed at the use of widespread construction practices are being covered.
\end{abstract}

Key words: Rigidity connection, lateral support element, lateral deformation, rigidity connection with infilled wall, rigidity shear wall.

\section{Introduction}

The research related with the preparations of precautions is intended to the prevention of lateral shape changes in compression struts and the evaluation of them has been started at the first years of the 20th century. It can be said that these research are the first approaches of the joints of column-beam and column-foundation rigidity constructions. Joint systems at normal direction in industrial buildings bearing systems, vertical and horizontal joint systems at normal direction to the beam plane at latice beams are few of those precautions. The contribution of the steel joint systems at industrial buildings ( steel rigidity wall, brace system) to the behaviour of the elements for which working for compression, the research for the effects of infilled walls to the behaviour of joint systems and the preparations of precaution which have practical importance are the current issues. There are a lot of different constructive regulations prepared at this stage of the design of steel construction which are intended to the joint bearing systems at industrial buildings. The research about this constructive

Corresponding author: Cemal Eyyubov, professor, research fields: steel structures, earthquake engineering and structural dynamic. formations and the classification of them in order to ease the choose of calculation methods still keeps up-to-date.

In this study, in order to research the contribution of the infilled walls to the behaviour of joint system, it is being used blend brick whose strength material is higher than $0.5 \mathrm{kN} / \mathrm{cm}^{2}$, and lime stone and also the strength of masonry mortar are being taken higher than $0.5 \mathrm{kN} / \mathrm{cm}^{2}[1]$.

\section{The Research of the Behaviours of Industrial Building Bearing System Compression Struts}

At industrial buildings, compression struts can be categorized in three groups according to their behaviour characters. These are industrial building columns, the compression struts of the industrial building joint systems and the compression struts of the industrial buildings' lattice beam systems. The results of the analysis of damage characters which came into surface during the use of these struts in building can be generalized as follows.

The detachment of cantilever spurs constituted for fitting the industrial buildings' under crane beams where heavy cranes are used can be often encountered. 
It has been come across the same characterized damages at the joint places of console beams which are used at steel melting divisions with columns. Damages, like the touch upon the melted metal or on slag and deflection of cross section elements at close places, the change of the cross section shape and local buckling, may happen.

The distanciation of the industrial building columns at frame plane and at the normal direction to the plane from vertical situation is a common damage type. This distanciation causes damage at the elements of building construction, the dissolution of construction elements' joints with columns, distanciation of crane roads from project situation, roof coating and destruction of the walls' water, sound and heat isolation therefore making the normal use of production division difficult. Despite the acceptance of the value of displacement of column head in respect to its foot as $0.001 \mathrm{H}$ at the specifications [2], in practice, this displacement can be taken up to $(0.0025 \sim 0.003) H$. Here, $H$ defines the height of the column. In one-to-one situations, the displacement value of the column head in respect to its foot can rise up to $0.01 \mathrm{H}$. This value can increase gradually in operating time. The measurement at an industrial building shows that the displacement of the column head in respect to its feet increased twice in a 5-year operating time [3].

Moreover, corrosion of column's parts where it touches upon with the ground, different wastes, water pipes whose isolation damaged creates danger as well. When the ground is humid where the column touches upon, 1 or 2 years would be enough for the consumption of the column cross section fully [1]. Separate knots of columns, the head, the spurs where under crane beams fitted, column feet, joint places of its elements with columns can create partial corrosion effects. Buckling characterized damages can be found less at rigidity connection system elements between columns.

Accidents like the loss of buckling endurance of roof lattice beams at struts working in compression, cracks where struts unifies at seam weldings on plates and deformation of the roof as a result of breakages can happen often [4].

Detailed control of roof beams shows that the common damages at roof lattice beams are vertical deflection of compression struts and vertical deflections, lateral shape change according to the lattice beam planes and deformation of bolts at brace joints. The control of roof bearing systems of industrial buildings indicates that lateral deflection of roof lattice beams is $(1 / 150) L_{1}$ [5]. Here, $L_{1}$ is the system length of roof lattice beams.

Less damage can be seen at the top head struts of the lattice systems. However, the deflection of bottom struts of lattice beams is a widespread damage type. In these struts, damages mostly due to the lateral deflection affect can be seen. The reasons behind these damages are the inability to form a hinge at the lattice beam support and rigid work of column-beam joint part, consisting compression stress at the side rod of the lattice beam bottom head and the vertical deflection effect seen at the struts measures internal forces [1].

Controls indicate that at the lattice beam's diagonal struts, more damages can be seen. It has been observed three times more damages at the diagonal struts working in compression than the diagonal struts working in tension. The proportion of deflection to the portion height varies between $1 / 500 \sim 1 / 300$. These portions take place at the normal direction to the beam plate. At the middle parts of the beam span, it has been observed more damages on the compression struts [6].

The control of the roof lattice beams of many industrial buildings of which used for a certain period of time shows that the damages seen at the lattice beams increase depending on the time of use. In addition to that, inspections reveal the buckling related damages increase with the rod slenderness accordingly. Flexures observed at lattice beam struts are much more higher at the normal direction of beam planes comparing to the beam planes [7]. 


\section{The Prevention of Lateral Deformation of Columns}

In Ref. [8], the result of the research related with the buckling of compression struts was published in 1902. Later, in Ref [6], it showed the possibility of preventing lateral shape changes of lattice beams' compression struts by supporting them with another rod laterally [6]. In the following studies, engineers and scientists prepared different constructive forms of prevention of lateral change shape of compression struts $[1,9,10]$. The simplest one among them is that the increase of the rigidity of compression rod point of junctions. Comparing to the buckling length of the compression struts point of junctions with linkage, their buckling length of the compression struts whose end points combined rigidly became two times less than the hinged one. The buckling length of both ends connects rigidly became four times less than compression rod whose one end is free and the other end connects rigidly. However, becoming rigid of the compression struts' end points usually would not be possible.

At industrial buildings, it can also be used vertical connection struts considered at different levels in column height like lateral supportive element. Besides, lintel beams of stone-brick infill wall can be used like lateral supportive elements at above of the window and door openings. Vertical wall columns of industrial building (3, 4) and supportive elements' (1, 2) placement diagram can be seen in Fig. 1. At the middle columns (4), lateral shape change is prevented with vertical connection rod (1) as two-way. When one of them works in compression, the other one creates tension effect. The reason of the rod's tension rigidity is bigger than compression rigidity, the prevention of lateral shape change at middle columns (4) would be actualized through tension rod (Fig. 1). Therefore, at middle columns (4), vertical connection rod will be considered as lateral support element (1). And, at the edge columns (3) since the vertical connection rod (2) unifies with column as one-sided, its lateral shape change (2) will be prevented with the principle of rod's working in compression. For both cases, the results of analysis of the behavior of the connection rod are given below.

\section{The Calculation of Middle Column Lateral Support Element of Industrial Building Longitudinal Wall}

If the stiffness of the lateral support element (1) is enough, the lateral displacement of middle columns prevented on joint section and buckling height of the column would be decreased twice. In this situation, the force affecting the vertical connection element can be calculated with

$$
Q=\frac{A \sigma_{e m}}{2.8 \sigma_{a}}
$$

If the calculations are made according to the ultimate strength, then the equation will be:

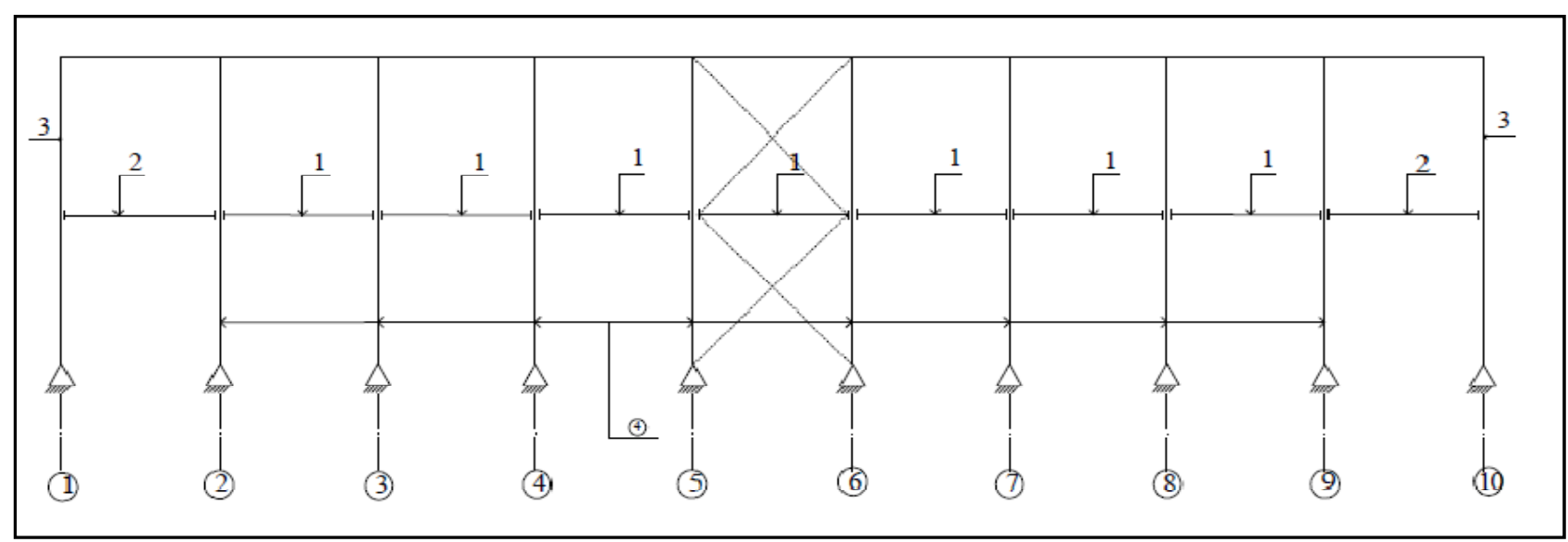

Fig. 1 The placement of the rigidity curtain and lateral support elements and the exterior on wall axis. 


$$
\begin{gathered}
Q=\frac{A}{2.8} \\
\text { Also, } Q=C \cdot N_{c r}
\end{gathered}
$$

where, $Q$ will be taken as $\mathrm{kN}$ type; $A=$ cross sectioning area, $C=0.02 \sim 0.025$ taken approximately [5]; $\sigma_{e m}=$ steel allowable stress; and $\sigma_{a}=$ yield stress.

At the situation where there is not any support element, lateral displacement of middle point of column can be calculated with

$$
f_{\text {maks }}=\left(\frac{\sigma_{a}}{\sigma_{k r}}-1\right) i \text { or } f_{\text {marks }}=\frac{0.0114 \lambda \cdot i}{\sigma_{a}-0.0114 \lambda}
$$

where, $\sigma_{k r}$ is critical stress of column cross section; $i$ is radius of gyration of lateral shape change of cross section; $\lambda$ is same columns' slenderness a same direction. Longitudinal deformation of joint element (1) can be calculated with

$$
\Delta l=\frac{Q l_{d}}{E_{d} A}
$$

The rigidity of the connection element on the direction of tension can be calculated with this equation, when $Q=1$ :

$$
K_{C}=\frac{1}{\Delta l}=\frac{E_{d} A}{l_{d}}
$$

According to Ref. [11], the support element is formed normally to columns and its stiffness to the tension effect will be calculated with Eqs. (4) and (4a).

Here, $Q$ is the value of shearing force that can be calculated with Eqs. (1) and (2a), $l_{d}$ is the length of connection rod, $E_{d}$ is the elasticity module of connection rod material and $K_{C}$ is the rigidity of the connection rod tension. At the end of the several numeric calculations of different column-support element systems, it can be seen that

$$
f_{\max } \gg \Delta l_{d}
$$

In this situation, it can be accepted that the formation of vertical support element prevents column middle point lateral deformations at the longitudinal wall axis.

\section{The Behaviour of Edge Column Lateral Support Element to Longitudinal Walls of Industrial Building}

The elements of pressure struts preventing buckling have to possess the minimum necessary stiffness in order to prevent buckling and the strength that will transfer the force resulting the buckling effect. During the design, the strength and the stiffness must be taken into consideration together and after the design completed according to strength, then the rigidity should be controlled. In this way, design can be made with the help of specially prepared abacs [12].

Below, It is given the analytic and the experimental results of the column-support element lateral shape change, behaviour of restrained support element with infilled wall.

\subsection{Analytical Study}

One of the methods providing the findings of critical buckling load of compression struts is the eigenvalue analysis. In this study, by using ANSYS finite elements sofware, compression struts' theoretical buckling loads were obtained with eigenvalue analysis and the effect of the infilled walls to the buckling behavior was investigated.

For the edge column of industrial building, 12-meter-height the I600 section is chosen, and as support element 6-meter-height $U$ section column which can adapt to infilled wall tied from column middle height connected (Fig. 2a). Upper end point of the column has vertical displacement freedom and both ends are hinged.

At first stage, imperfect column's theoretical buckling load and mode shapes are obtained without support element by defining displacement at the ratio of $1 / 500$ of height to the column's middle point (Fig. 2b). For this, it is given 1 unit force to the column's top point, and via eigenvalue analysis the buckling load is found as $779.90 \mathrm{kN}$ section's second mode buckling force is $3,131.61 \mathrm{kN}$. 


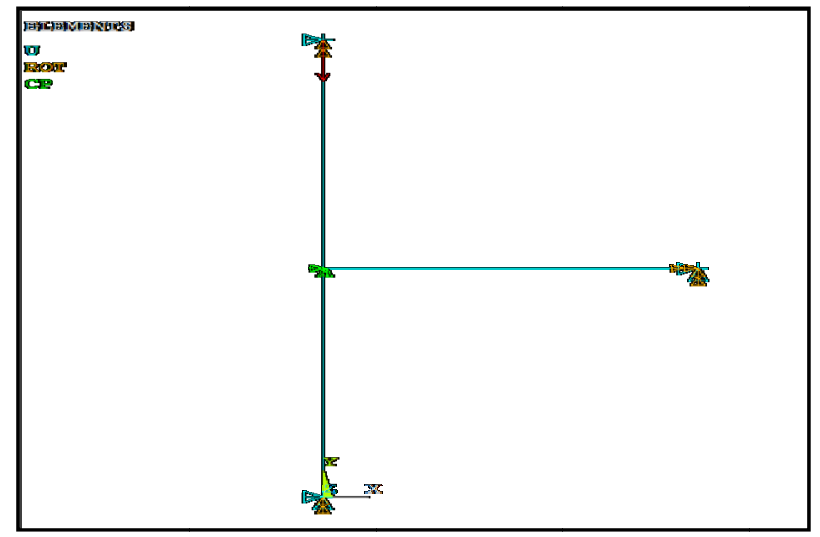

(a)

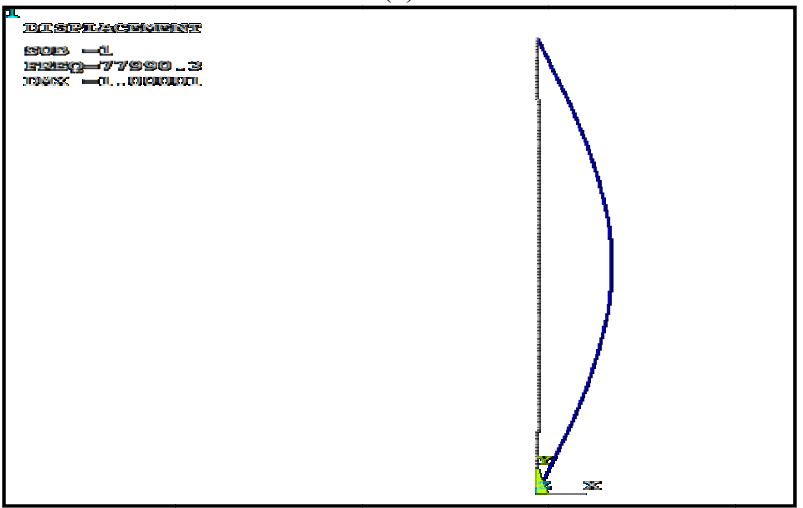

(b)

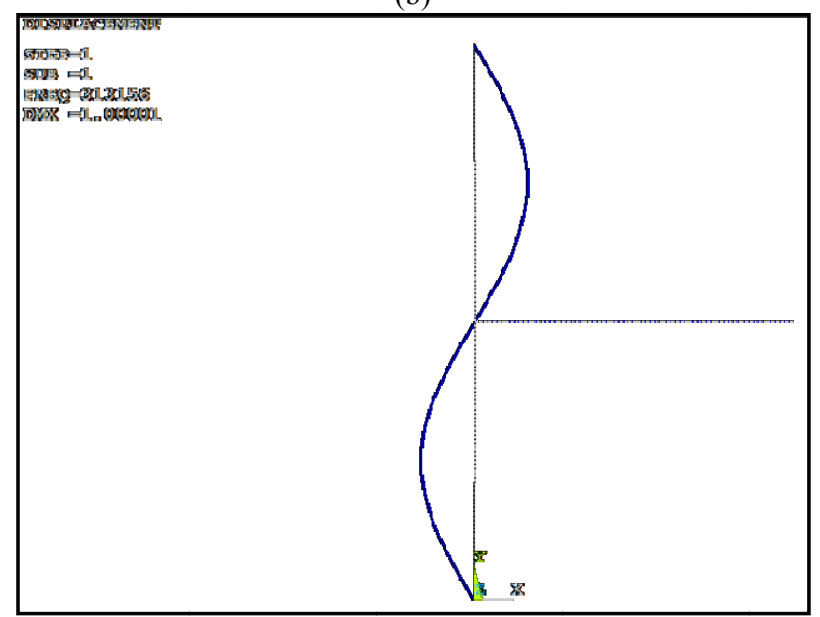

(c)

Fig. 2 Analysis model of column-support element and mode shapes: (a) connection model of edge column-support element; (b) imperfect Column 1, buckling mode; (c) buckling mode when U120 support element used.

As a result of the repetitive analysis, various $U$ stage features were assigned to the support element in order to determine the section preventing buckling from column's middle point, at Mode 1 to be able to reach 3,131.61 kN buckling load, the necessary minimum section is decided as U120 (Fig. 2c). At the U100 section, the buckling force is acquired as $2,498.26 \mathrm{kN}$ and cannot prevent the column from buckling.

At final stage, it has been studied whether or not can be reached column force eliminated from buckling in the case of the use of U100 sectioned support element by benefiting from infilled wall stiffness. If possible, the minimum value of infilled wall elasticity module is researched. For this, two dimensional plane stress elements are defined representing the infilled wall throughout the span length, and values are assigned as the horizontal elasticity module has the half of the vertical elasticity module's values. Compression springs are placed between column and support element forming calculation model and plane stress element representing infilled wall (Fig. 3).

The acquired values at analysis: horizantal $E_{x}=$ $85 \mathrm{kN} / \mathrm{cm}^{2}$, vertical $E_{y}=170 \mathrm{kN} / \mathrm{cm}^{2}$ for infilled wall $P$ $=2,989.10 \mathrm{kN}$, horizantal $E_{x}=100 \mathrm{kN} / \mathrm{cm}^{2}$, vertical $E_{y}$ $=200 \mathrm{kN} / \mathrm{cm}^{2}$ for infilled wall $P=3,045.77 \mathrm{kN}$, horizantal $E_{x}=115 \mathrm{kN} / \mathrm{cm}^{2}$, vertical $E_{y}=230 \mathrm{kN} / \mathrm{cm}^{2}$ for infilled wall $P=3,096.80 \mathrm{kN}$, horizantal $E_{x}=$ $125 \mathrm{kN} / \mathrm{cm}^{2}$, vertical $E_{y}=250 \mathrm{kN} / \mathrm{cm}^{2}$ for infilled wall $P=3,127.96 \mathrm{kN}$.

In the situation of the use of infilled wall whose vertical elasticity module is $250 \mathrm{kN} / \mathrm{cm}^{2}$ with the $\mathrm{U} 100$ support element, the column force prevented from buckling will be reached. Solid brick compression strength $\left(E=550 f_{\mathrm{cm}}\right)$ should be $0.45 \mathrm{kN} / \mathrm{cm}^{2}$ approximately [13].

\subsection{The Evaluation of the Literature Data of Support Element Behaviours}

At edge column (3), lateral support element (2) is unified with column as one sided. In this situation, the tension stiffness of the lateral support element will be much more than compression stiffness, edge column deformation will be like the example given in Fig. 2a. The minimum stiffness value of support element in order to prevent the deformation like Fig. 2b is:

$$
K_{b}=\frac{4 N_{c r}}{l}
$$

It may be determined by connections [6]. The force 


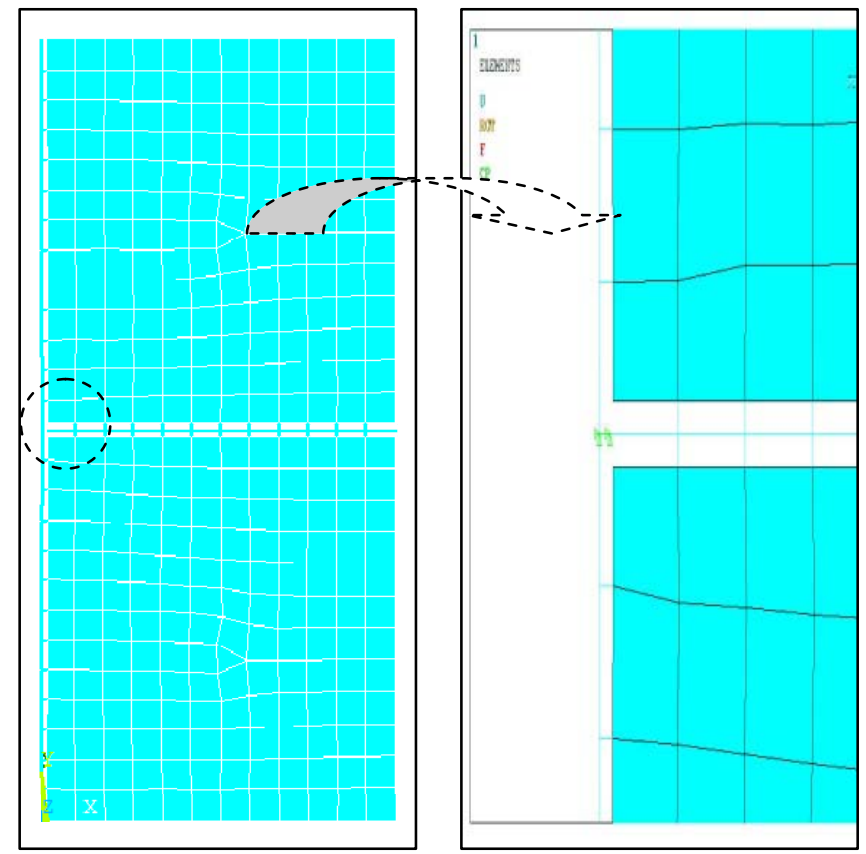

Fig. 3 The placement of pressure springs between column-support element and infilled wall.

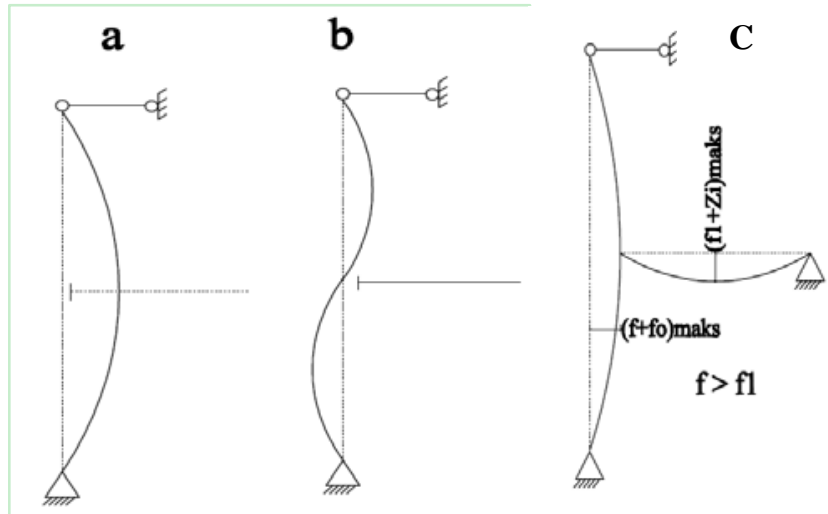

Fig. 4 Buckling characters of columns.

Notes: $a, b$ - edge column depends on the stiffness of the support element column buckling character; $c$-deformation character of column and lateral support element system;

$f_{0}$-fault value of compression rod;

$Z_{i}$ - vertical fault value of support element.

on the support member due to column axial load with the initial imperfection $e_{0}$, calculated [14]:

$$
\frac{Q}{N}=\frac{e_{0} / L}{\left(\frac{N_{E}}{N}-1\right)} \times \frac{1}{\frac{N}{K L}+\frac{1}{2 \pi \sqrt{\frac{N}{N_{E}}}} \operatorname{tg}\left(\frac{\pi}{2} \sqrt{\frac{N}{N_{E}}}\right)-\frac{1}{4}}
$$

where, $Q$ is the restraint force; $N$ is the axial load; $K$ is the restraint stiffness; and $N_{E}$ is the Euler buckling load.
Many generalization of literature data to examine the structure of the column height of the column prevents the lateral displacement in the different levels given in Fig. 4 [15]. In this study, we indicate that the initial curvature of the column and a lateral support element remain in its elastic limit. Winter articulated adopted as the support member ports in subsequent studies [16]. In this study, internal force on the support element due to the elastic load in the column was determined and the minimum stiffness. 
The column-support member combination connection joint displacements depending on the loading of the column can be calculated using the following equation [11]:

$$
f=\frac{\pi^{2} Q\left(2-\frac{Q}{H_{E}}\right) z_{i}^{2}}{4 l_{d} H_{E}\left(1-\frac{Q}{H_{E}}\right)^{2}}+\frac{\pi^{2} Q l_{d}}{H_{E}\left(\frac{l_{d}}{i_{d}}\right)^{2}}
$$

where, displacement changes depending on the way the first term and the second term represents the axial shortening effect of uniform load, $Q$-when the column load resulting internal forces in the support element; $H_{E}$-support element Euler buckling load; $i_{d}$-support element minimum cross-sectional radius of inertia; $z_{i}$-pre-existing lateral imperfection of the support element.

In Ref. [11], code with maximum buckling load specification is given in relation to situations where different forms of pressure bar on the prevention of buckling defects.

$$
\begin{gathered}
\left.N_{u}=N_{K}\left[\frac{\frac{\varepsilon_{y}}{\varepsilon_{k}}+\eta+1}{2}-\sqrt{\left(\frac{\varepsilon_{y}}{\varepsilon_{k}}+\eta+1\right)^{2}}\right)^{2}-\frac{\varepsilon_{y}}{\varepsilon_{k}}\right] \\
\varepsilon_{K}=\frac{N_{K}}{E_{K} A_{K}} ; \varepsilon_{K}=\frac{\pi^{2}}{\left(\frac{l_{K}}{i_{K}}\right)^{2}} ; \varepsilon_{y}=\frac{\sigma_{a}}{E} ; \\
\eta=3.10^{-5}\left(\frac{l_{K}}{i_{K}}\right)^{2}
\end{gathered}
$$

where, $A_{K}$-column section area; $\varepsilon_{y}$-yield strain of column-lateral support element junction material; geometric parameters of the $\eta$-column imperfection parameter; $l_{k}$-column unbraced length; $i_{k}$-the minimum radius of inertia of the lateral support element cross section; $\varepsilon_{k}$-critical strain value. Specification working diagram of the system as column-support element is as shown in Fig. 2c.

In the case of also imperfection presence in the support element, the calculation method is becoming more complex.

Column-side support member tension according to the maximum value in the combination can vary from $0.6 \sigma$ [11] with a $0.66 \sigma$ maximum pressure loading occurring on the support element

$$
Q=\frac{1}{2} H_{E}\left[\frac{\varepsilon_{y}}{\varepsilon_{E}}+\eta+1-2 \times \sqrt{\left(\frac{\frac{\varepsilon_{y}}{\varepsilon_{E}}+\eta+1}{2}\right)^{2}}-\frac{\varepsilon_{y}}{\varepsilon_{E}}\right](10)
$$

can be calculated like here. And

$$
\begin{gathered}
\varepsilon_{E}=\frac{\pi^{2} i_{d}^{2}}{l_{d}^{2}} \text { or } \varepsilon_{E}=\frac{H_{E}}{E_{d} A_{d}} ; \\
\eta=3.10^{-5}\left(\frac{l_{d}}{i_{d}}\right)^{2}
\end{gathered}
$$

The method is used based on the estimation of the complex and based on estimation. Have great stiffness and buckling resistance of the support member for the compression struts is often not a feasible solution.

\section{Edge Column Lateral Support Staff Regulations of Industrial Building Longitudinal Wall}

Second item of this article during the use of the building columns, depending on the analysis and generalization of the defects that occur in the lateral support element and the adoption of certain mathematical connection varies depending on time are very difficult. Accepted approaches (Eqs. (9a) and (10a)) are based on the large estimates. In the stage today of building structural systems design, fulfillment and lateral support members with the task of preventing the lateral stiffness of the large deformation of the pressure bar have a greater practical significance. This lateral support member can be selected so that the degree of slenderness $\lambda \leq 40$ constructive measures that are appropriate to the rigidity value of lateral support element can be classified as follows:

(1) Steel sections constituting the parts when the lateral support elements. A few examples of this 
constructive embodiment is illustrated in Fig. 5. Furthermore, the inner and outer column of the occurring shearing forces in a column in the desired position of the lateral deformation must be provided to transfer to the other column end point. It is given the analysis of constructive prepared according to the following scheme. In Fig. 5, the side columns (3) formed on the edge of the column-supporting element

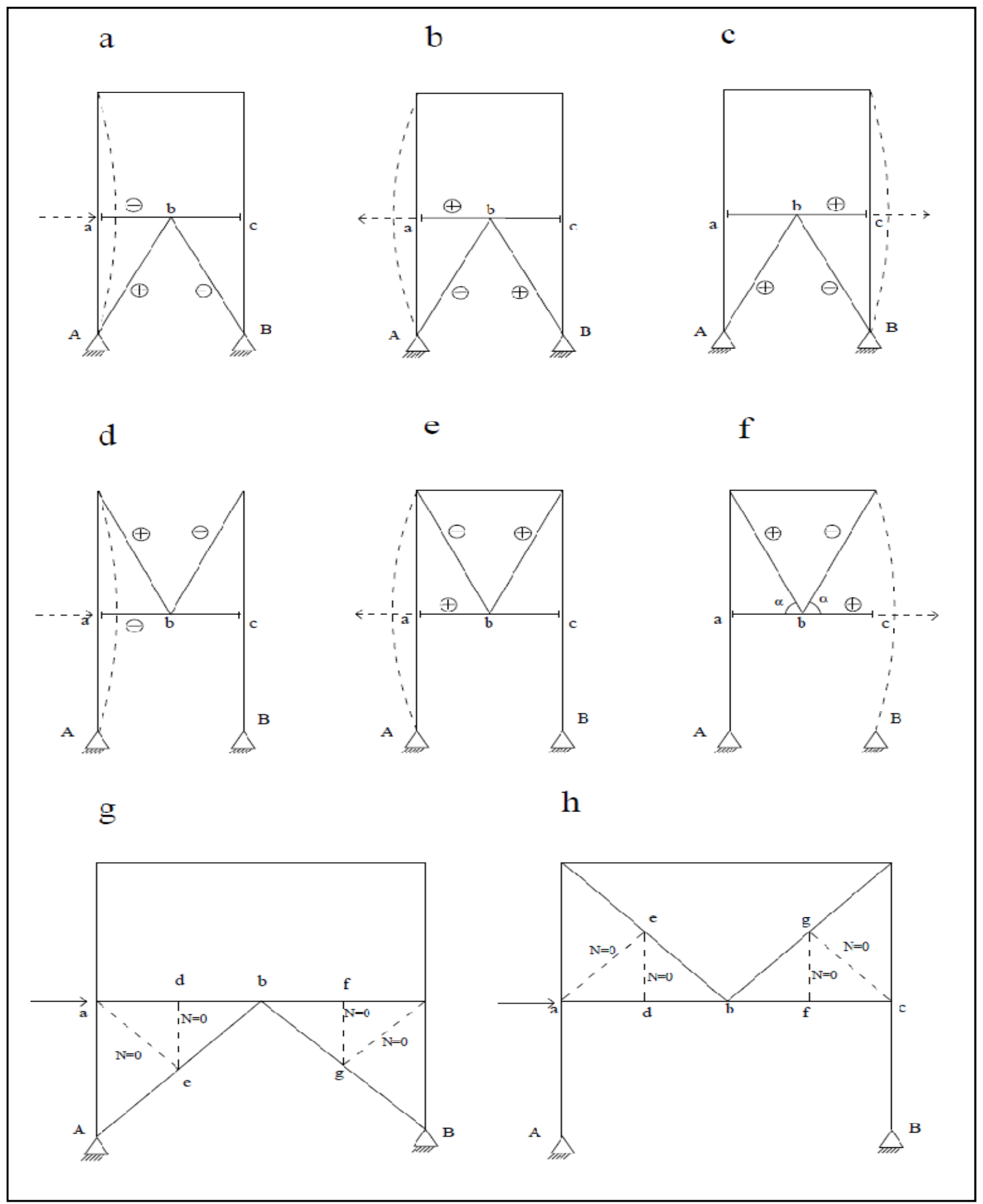

Fig. 5 Elements constituting the support of the steel profile. 
of the lateral support element arrangement (2) junction point (a) effects $Q$ force principle of providing the transfer to the column bottom and the top end by changing the orbit is used. Wherein, further support elements (2) change in length can be shortened and reduced pressure bar laterally. Thus, the implementation of Fig. 5 constitutes the edge in the column (3) reacting the resulting lateral deformation of the inner column (4) transfer inhibited and not contributes to the internal column buckling strain of this value. The support element as part of the lab length $\leq 40 i$ can be more effective according to the selection condition. Here is an example of the arrangement of lateral support element. However, with the same purpose, it can also be applied to other forms. Edge column (3) of the same column and the resulting shear forces must be changed to transfer orbit to the next mid-column bracket (see Fig. 5). The distribution of the internal forces on the lateral support member arrangements are given in Figs. 6 and 7. As the requirements of the design conditions of the angle which is consisting the cross members forming the lateral support system with the horizontal; if it is smaller than $45^{\circ}$, buckling length of the elements can be reduced by using the formings given in Fig. 5 ( $\mathrm{g}$ and $\mathrm{h}$ );

(2) The two sides transverse to the longitudinal wall bearing system that frames the space between the concrete rigidity, Fig. 1 curtain between 1-2 and 9-10

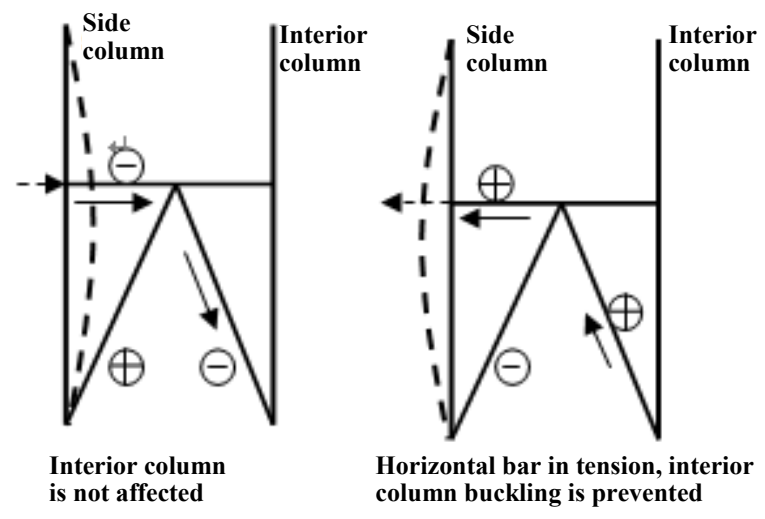

Fig. 6 Buckling of the side column

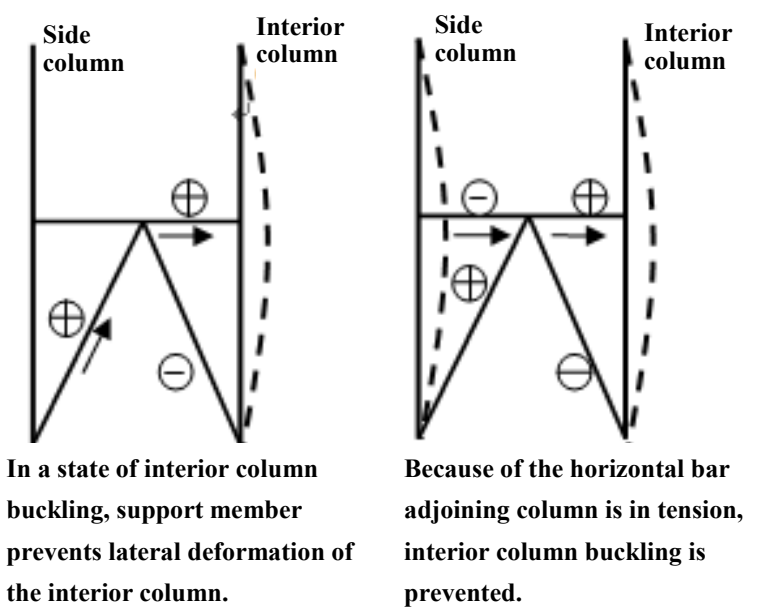

Fig. 7 Buckling of the interior column.

constitute axes. In this case, the two sides reinforced concrete wall to prevent colon exactly the lateral deformation and buckling resistance of the column with this application to the border will raise short column strength;

(3) Cross-frame of 1-2 and 9-10 axis (Fig. 1) between the space to fill with stone and brick masonry, infill frame of the building of the long walls to create a system it is possible to prevent an edge change column laterally. In order to achieve this, the bonding mesh technic which ensures good contact of the edge of the infilled wall and the edge of the longitudinal wall's side column (3) should be applied. This theme mesh infill be equipped with a depth of $1.5 \mathrm{~m}$ to provide good purposes. Reinforcement mesh of a tip edge of the column (3), the source is coupled, the other end is inserted into the depth of $1.5 \mathrm{~m}$ mesh. The distance from each other in the column height of the reinforcement mesh should be up supply $l_{1} \leq 40$. This approach is often very difficult. Accordingly, the height of the lateral edges of the column support member will prevent the lateral deformation level (typically the column axis) which can be considered. This lateral support element of Fig. 1 also constitutes the axis 1-2 and 9-10 will be integrated on both columns. This element or elements on the frame and the remaining space under the stone or brick masonry is built with spaces (Fig. 8). Here, the lateral support 

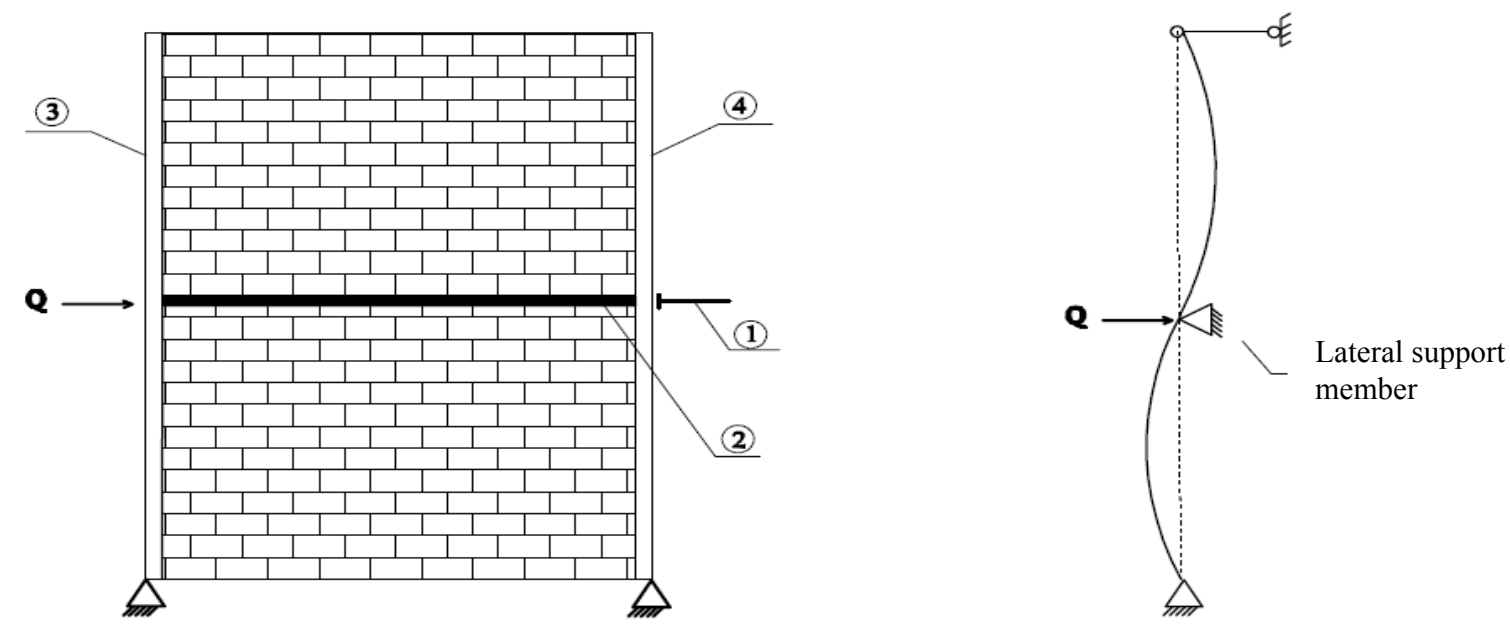

(a)
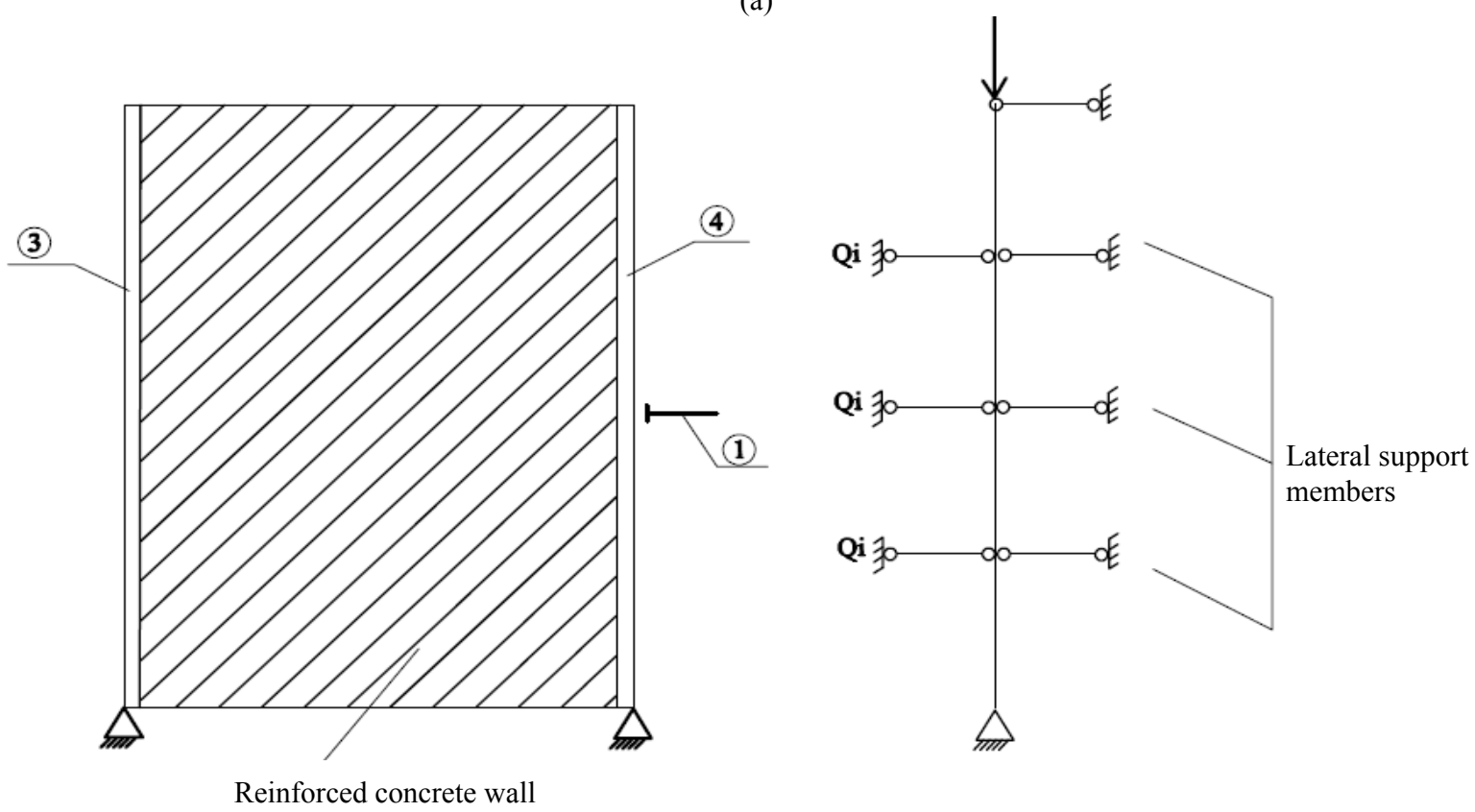

(b)

Fig. 8 Infilled lateral support member arrangement: (a) reinforced concrete shear wall lateral support element; (b) lateral deformation of the stone-brick infill wall lateral support element.

element (2) shear forces occurring can create crush the organization. This crush resistance control:

$$
\sigma_{e z}=\frac{Q_{1}}{b h_{p}} \leq \sigma_{e z, e m}=R_{\ddot{o}} \xi
$$

made by relation. Wherein, $Q_{1}$ - shear strain occurring in the lateral support member is the value of the pressure element:

$$
Q_{1}=C Q
$$

calculated by formula. Here maximum calculated by
Eqs. (2) or (2a) of the effects of pressure load on the $Q$ - side support elements; $C$ coefficient will be considered with the approach applied in Eq. (2); $h_{p}$ - knitting surface leaning profile height (width) is determined depending on the chosen profile and geometric characteristics are taken in centimeters. As the length of $b$ is the length profile leaning on the wall, $b=5 \mathrm{~cm}$ [1]. Figure for the masonry of stone and mortar strength depends experimental designated as 
compression strength, compression strength from $\xi$-formal transfer coefficient is the crushing strength which can be selected as $\xi=1.2 \sim 1.5$ [1].

This high-strength material with mesh infill as the stone-brick and mortar will be used. For example, the resistance of the stone and brick used to this organization from $0.5 \mathrm{kN} / \mathrm{cm}^{2}$, the masonry mortar strength of $0.5 \mathrm{kN} / \mathrm{cm}^{2}$ will be greater than this. The adhesion strength of the mortar with stone-brick $0.012 \mathrm{kN} / \mathrm{cm}^{2}$ will be required to be provided more [17]. In this case, the mesh prevents the edge of the lateral support element column vertical deformation. The cross section of the lateral support element is calculated according to the column, the lateral edges of the support member attaches to the occurring shearing forces. Wherein the lateral support member may be sized to the short-bar working pressure characters. $Q$ shear value of $1,2,7,13$ and 15 can be calculated by equations.

Changing the infill panels laterally towards the edge of column block with examples of constructive forms are given in Fig. 8 .

\section{Conclusions}

Investigation of the pressure rod for inhibiting formation lateral strain on the results of the study can be summarized as follows:

(1) The generalization of the results of the examination and conditions of use during the use of industrial buildings, limits permitted in the specifications of the column headings displacement relative to the foot showed that exceed $2 \sim 3$ times. Damages caused by errors in making and using the pressure bar of the rafters have been identified. It was observed that the pressure of the truss rod system in the filings of the longitudinal rate of $1 / 150$ and reached higher values, the same error in lateral support element of the column (belts, beams, connecting struts) were also observed. This is given as a mathematical error in generalizing the connection is very difficult in today's stage;
(2) Industrial buildings, social, cultural buildings, the calculation of the column with a big height of buildings such as sports facilities ensure the prevention of lateral strain that the implementation of structural measures can enable the implementation of more cost-column design;

(3) Lateral support element, which can be used to prevent the lateral shape change of columns, will constitute in a form of pressure rod whose buckling is prevented. The longitudinal rigidity of this support member 4, 6, 15 no line can be calculated by formulas. Lateral support elements of the columns of the constructive forms given in this article (Figs. 5 and 8) can be designed by selecting one;

(4) Exploited infill stiffness for buckling prevention. I600 remaining insufficient to prevent buckling of the columns supporting element U100, elasticity modulus $25,000 \mathrm{~kg} / \mathrm{cm}^{2}$, which reached a sufficient buckling resistance by filling the wall rigidity. Filling the spaces to be used in brick wall resistance pressure must be greater than $50 \mathrm{~kg} / \mathrm{cm}^{2}$.

\section{References}

[1] Eyyubov, C. 2015. Steel Structures. Vol. 1. İstanbul: Birsen Publishing. (in Turkish)

[2] SNIP II.23-81. 1988. Stalniye Konstruksii, Stroitelniye Norm i Pravila Normı Proyektirovaniye (Construction Norm and Rules of Steel Structures). Moscow: Constructional Publishing. (in Russian)

[3] Kikin, A. İ., and Vasiliyev, A. A. 1984. Povışeniye Dolgoveçnosti Metaliçeskix Konstruksiy Promışlennıx Zdaniy (Increasing the Durability of Metal Constructions of Industrial Buildings). Moscow: Constructional Publishing. (in Russian)

[4] Laşenko, M. N. 1966. Avarii Metaliçeskix Konstruksiy i Soorujeniy (Accidents in Metal Constructions and Engineering Structures). Leningrad: Constructional Publishing. (in Russian)

[5] Eyyubov, C., Yılmaz, C., and Yaltır, Ş. 2015. "A Sequence Problems about the Investigation of Truss Members Behavior." Yapı Dünyası Journal March-April: 228-9.

[6] Eyyubov, C. 2015. Steel Structures. Vol. 2. İstanbul: Birsen Publishing. (in Turkish)

[7] Nikifirov, S. N. 1968. Ustoyçivost Sjatıx Sterjney (Stability of Compression Struts). Moscow: 
Constructional Publishing. (in Russian)

[8] Timoshenko, S., and Gere., J. 1961. Theory of Elastic Stability. New York: McGraw Hill Book Company.

[9] Vatansever, C., and Yardımc1, N. 2009. "A Thin Plated Steel Shear Walls Hysteretic Behavior and Experimental Investigation." In National Steel Structures Symposium Proceeding Book. Gaziantep.

[10] Konstruksii, M., and Proyektirovşika, S. 1980. Metal Construction, Designers Hand book. Moscow: Constructional Publishing.

[11] SAA (Standards Association of Australia). 1988. Building Code of Australia. SAA.

[12] Gardner, L. 2011. Stability of Steel Beams and Columns. Berkshire: EC3.

[13] Eyyubov, C., Hasnalbant, M., and Eyyubov, İ. 2015. "The Investigation of the Deformation of Structural Members to the Bearing System Behavior." In National Steel Structures Symposium Proceeding Book, 303-16.

[14] Banfi, M. 2002. "Discussion on Stiffness of Restraint for Steel Struts." In Proceedings of the Institution of Civil Engineers - Structures and Buildings 152 (3): 298-300.

[15] Mutton, B. R., Stud, B. E., Aust, J. E., and Trahair, N. S. 1975. "Design Requirements for Column Braces." Civil Engineering Transactions, Paper No: 3390.

[16] Winter, G. 1960. "Lateral Bracing of Columns and Beams.” ASCE Transactions 125: 809-25.

[17] Eyyubov, İ. C. 2009. "Karkas gözü Doldurucu Divar Hörgüsünün Mexaniki Xüsusiyetlerinin Tedqiqi. Azerbaycan Respublikası Tahsil Nazirliği (Investigation of the Mechanical Properties of Infill Wall Mesh)." Nazari ve Tatbiqi Mexanika Jurnali 2: s.27-33. (in Russian) 